\title{
Interdisciplinary Research-Mathematical Interactions Viewed from Four Portrayals
}

Goong Chen

\section{Introduction: Interdisciplinarity with Mathematics}

You've been approached by a colleague from the college of agriculture at your university, asking you to help solve a mathematical problem. You've pondered curious problems from engineering, physics, chemistry, biology, or social sciences and wanted to delve deeper into them. You've read calls from funding agencies inviting mathematicians' participation, and suddenly someone from another department of your university is organizing a drive to submit a group proposal and is giving you a cold call to solicit your input and cooperation. He is also promising a share of summer grant support for you if the proposal is funded.

Do any of the above situations sound familiar to you? If not, then you will surely encounter these scenarios more and more in the future. We are living in an ever more complex world. Interactions among mathematicians themselves and, more importantly, engagements between mathematicians and those in other disciplines are on the rise. Interdisciplinary research involving mathematics almost inevitably is becoming the trend, as the universality of mathematics can be felt in so many different forms. A quick survey of several major contemporary research themes shows

Goong Chen is professor of mathematics at Texas A\&M University (TAMU) and Texas A\&M University-Qatar. He is also a member of the Institute for Quantum Science and Engineering at TAMU. He gratefully acknowledges partial support by grant NHARP-010366-0149-2009 from the Texas Higher Education Coordinating Board and by the Qatar National Research Fund's grant National Priority Research Project (NPRP) 4-1162-1-181. His email address is gchen@math. tamu . edu/.

DOI: http://dx.doi.org/10.1090/noti892 what relevant disciplines are involved and where mathematical components are either present or in demand:

(A) Bioinformatics: biology, computer science, probability and statistics, medicine, systems theory, combinatorics, optimization, ...;

(B) Nanotechnology: physics, chemistry, electrical and chemical engineering, mathematical analysis, ...;

(C) Genomics: genetics, molecular and cell biology, biochemistry, scientific computing, ... ;

(D) Proteomics: pharmaceuticals, biology, chemistry, physics, scientific computing, ...;

(E) Conflict and resolution: sociology, psychology, political science, game and control theory, stability and chaos, ...;

(F) Homeland security and the war on terrorism: engineering, cybernetics, finance and banking, cryptography, social sciences, linguistics, search algorithms, tomography, mathematics in general, ...;

(G) Renewable energy technology: engineering, physics, chemistry, fluid dynamics, computational mechanics and mathematics, ...;

(H) Climate change and global warming: atmospheric science, chemistry, physics, oceanography, glaciology, forestry, soil science, mathematical modeling, ....

According to a 330-page government- and industry-commissioned report published by the National Academy Press [2], a definition is given as follows:

Interdisciplinary research (IDR) is a mode of research by teams or individuals that integrates information, data, techniques, tools, perspectives, concepts, and/or theories from two or more disciplines or bodies of 
specialized knowledge to advance fundamental understanding or to solve problems whose solutions are beyond the scope of a single discipline or area of research practice.

Clearly, the topics listed in (A)-(H) must be administered in such a way as to achieve success. Interdisciplinary research necessarily is the only way that scientists, mathematicians, engineers, and social scientists can collectively contribute and share their different specialized perspectives, knowledge, and skills to address wide-ranging issues and attack pressing real-world problems that no single discipline alone can resolve [1]. New opportunities are constantly emerging for mathematicians to participate in interdisciplinary research.

The conduct and management of interdisciplinary research can be coarsely divided into three classes according to their scales:

(i) Macro-scale: A project on the national scale requiring great commitment of resources. An example is the Manhattan Project, which was imperative for a wartime nation, or a mission to the moon.

(ii) Meso-scale: Interdisciplinary research activities conducted at the levels of universities, colleges, institutes, departments, commercial companies, etc., where hirings of clusters or mission-/objective-oriented team formations are made, often driven by funding, budget availability for interdisciplinary research support structures, or the development of targeted products.

(iii) Micro-scale: Interdisciplinary research activities conducted by just a few individuals, based on necessity or otherwise simply out of curiosity.

There exists a large amount of literature on interdisciplinary research, for instance articles $[3,4,7,8,9,10,11]$, where interested readers can see the effects and benefits of, barriers to, funding for, and management and educational programs of interdisciplinary research. Most of them deal with macro- and meso-scale interdisciplinary research, especially the latter. There are now many mathematical science institutes in the United States and the rest of the world where activities in applications of mathematics and interdisciplinary research are bustling. This marks a significant change and progress over two decades ago. Even so, at the most fundamental level, interdisciplinary research still depends on interactions between individuals regardless of whether the actions take place within or outside any academic institute or program. For this reason, the author is writing this essay on interdisciplinary research in narrow mode, only at the micro-scale (iii) level. It was meant to be written in a narrative manner in the hope of conveying and sharing some real sense and experience rather than the abstract notion of what "interdisciplinary mathematical research" is about. The author considered making the presentation in anonymous, third-person form in order to minimize any egocentric tendency, but had to give up that when faced with the need to cite pertinent references wherein his name appears as coauthor. In what follows, the author will revert to the first person "I". I write about my life-changing personal experiences in working interdisciplinarily, viewed through the portrayals of four outstanding collaborators. This article is not about me-rather, it is about collaboration in practice in which I was an active participant. I beg the reader's understanding in advance.

During my career as an applied analyst and applied mathematician, I have worked with many researchers outside mathematics. Many of my papers are not published in traditional mathematics journals. For example, only about 75 percent of my papers/books are listed in MathSciNet of the American Mathematical Society. I am guessing that the reason for this is that many of my papers were published in engineering, physics, and chemistry journals. Owing to my strong personal interests in various problems originating from engineering and science, I have a good number of collaborators who are not mathematicians by discipline. In the following four sections, I describe my work with four of these collaborators as some of the highlights.

\section{Dr. Philip J. Morris, Aerospace Engineer}

In the late 1970s I was just a young assistant professor teaching in the math department of Penn State University, whose engineering college has a strong reputation. I was assigned to teach graduate-level numerical analysis courses annually. I noticed that in my classes there would always be a number of high-quality graduate students from the aerospace engineering department. Pretty soon I learned from them that they were sent to take my course by their advisor, Dr. Morris.

Dr. Morris was an associate professor of aerospace engineering at that time, six years my senior. His specialties are aeroacoustics, turbulence modeling, and computational fluid dynamics (CFD). As with many engineering faculty and scientists from western Europe, his mathematical background is strong. Even though occasionally he joked about mathematicians' obsession with rigor and proofs, he really cared about mathematics, whether theoretical or numerical. Dr. Morris confided that actually he had never taken a graduate class in math; in retrospect, he believes that he would have benefitted very much, and this is why he encourages his graduate students 
to take as much applied mathematics as they can fit into their schedules.

One amusing story comes to mind when reminiscing about one of his graduating students in a Ph.D. defense exam. I asked that student, "What is the definition of a Hilbert space?" The student staggered. Dr. Morris came to the rescue by saying that he thought that the Hilbert space was the office occupied by Professor David Hilbert at Göttingen.

Dr. Morris has written many numerical subroutines and software for the computation of aeroacoustic and fluid fields. His designs of such algorithms are rather ingenious and elegant, featuring high-order asymptotic and perturbation expansions and Gaussian quadratures. Over his career, he and his graduate students have produced and accumulated a large amount of such custom-designed numerical software. Many of his subroutines have required long periods of development and have the capability to predict jet or underwater acoustic fields. Dr. Morris's personal stockpile of aeroacoustic numerics probably is the largest in the world. He does not do classified research, but he does need to be aware of ITAR (International Traffic in Arms Regulations) issues regarding the usage of his code by non-U.S. persons in order to safeguard U.S. national security and to follow the U.S. Arms (and Technology) Export Control Act.

Dr. Morris has always been rather generous toward me regarding the usage of his numerical software. During that time, my collaborator, Dr. Jianxin Zhou, and I spent a good deal of time developing boundary element methods (BEM) for numerical solutions of PDEs. In the process, the numerical quadrature and approximations of special functions such as Bessel, Hankel, Mathieu, Struve functions, etc., are needed. With invaluable help from Dr. Morris and a couple of his Ph.D. students, Dr. Zhou and I were able to develop boundary element numerical schemes of high accuracy. Our efforts in this direction came to fruition in the publication of a BEM book (Chen and Zhou [12]) by Academic Press in 1991. This book was further revised and expanded to include some nonlinear equations. Its new edition was published in 2010 by Atlantis Press [13].

Dr. Morris and I-sometimes together with his Ph.D. students-have written about half a dozen papers. In one of the papers, ideas from BEM were used in the calculation of jet noise. He listed me as a coauthor. The paper later won an American Institute of Aeronautics and Astronautics (AIAA, the professional society for aerospace engineers) Best Paper Award at the AIAA 12th Aeroacoustics Conference in San Antonio, Texas, in 1994. I must confess that my contributions to that paper were minimal.

Dr. Morris does extensive consulting for industry and government. He regularly attends panel meetings and reviews at NASA, DOD, and DOE labs. He also visits the General Electric, Pratt \& Whitney, and Rolls Royce jet engine divisions in order to talk with factory technical staff and management. One day, he asked me to help him to review the mathematics portion of a European engineering research proposal related to the liquid fuel-sloshing motion in a satellite. This was a new experience, as I had never dealt with any "real-world" research problems in applied math. I tried to read carefully the fluid-dynamic partial differential equations and the proposed numerical schemes, and managed to write a page of comments as a review report for Dr. Morris. In reflection, I must again confess that I probably did not do a first-rate job, as the only things I knew up to that time were textbook derived. A week later, Dr. Morris submitted his review report to the soliciting European agency and an honorarium check followed, which he generously shared with me for my services. I asked him what the recommendation and conclusion of his review report was. He said that the mathematical model of the fuel-sloshing motion is incorrect. Therefore, the proposal had to be rejected or significantly modified. I kicked myself for not having discovered this fundamental point. But in my own defense, during that time (the early 1980s when this event took place), mathematical modeling was not yet the focal topic in applied math that it is today. Applied mathematicians in that era tended to study whatever problems, in formulated form, were given to them. That explained and led to my failure to scrutinize a most fundamental issue of the correctness of the modeling PDEs. Dr. Morris himself obviously knew the fuel-sloshing motion well, but as far as the instability of sloshing fluid motion in a satellite fuel tank is concerned, he was further aided at that time by a Ph.D. student, Thomas J. Bridges, who had studied such a research problem quite carefully elsewhere three years before. Bridges's insights and input helped Dr. Morris to discover the deficiency of the proposal's mathematical model. Bridges also shared part of the consulting fee from Dr. Morris. I have written a couple of joint papers with Dr. Bridges, who later became an applied mathematician (but his Ph.D. degree was in aerospace engineering) and has made a brilliant mathematical career for himself.

I left Penn State University in 1987. Within a couple of years, Dr. Morris was given the prestigious endowed Boeing/A.D. Welliver Professorship at Penn State's aerospace engineering department, a position that he continues to hold to this day. 
After my departure, the spatial separation has diluted our opportunities to interact closely for more than two decades. But two years ago we again found common interest, this time in wind energy research, so he and I joined forces on writing research proposals. This year (2012), we again wrote several papers together. Even if funding for those proposals is not successful, we still plan to write a couple of joint papers together on the basis of our recently renewed discussions.

\section{Dr. Marlan O. Scully, Physicist}

Dr. Scully is eleven years my senior. He is an accomplished physicist with whom I became acquainted through the introduction of a mathematical physicist colleague, Dr. Stephen A. Fulling, in my math department at Texas A\&M. When I first met him during the mid/late 1990s, Dr. Scully held a membership in Academia Europaea (The Academy of Europe). A few years later he was elected a member of the U.S. National Academy of Sciences.

Dr. Scully comes from an outstanding physics lineage. His academic great-grandfather is Max Born. (Max Born wanted to study mathematics under David Hilbert at Göttingen, but Hilbert soon recognized that Born had even greater talent in physics, so Hilbert advised Born to take up physics instead [16]. Born's doctoral dissertation was supervised by Carl Runge of Runge-Kutta fame, and Born won the 1954 Nobel Prize in physics (shared with Walther Bothe).) Dr. Scully's academic grandfather and father are, respectively, J. Robert Oppenheimer and Willis Lamb. Lamb shared the Nobel Prize in physics in 1955 with Polykarp Kusch. Dr. Scully has written many joint papers with Nobel physics winners: Glauber, Lamb, Schwinger, Townes, etc. Dr. Scully founded the Institute for Quantum Science and Engineering (IQSE) on campus. IQSE has hosted many Nobel physicists. I often wonder if I may be the mathematician who has shaken the hands of the most Nobel physicists through my affiliation with IQSE.

Dr. Scully has a great love for physics. He also has great respect for mathematics, for the useful role that mathematics plays in physics. He often evaluates complex contour integrals himself and challenges me. (Remember those real or complex improper integrals requiring the choice of special infinitely long paths and residue evaluations?) He once claimed that about 60 percent of the mathematics used in physics involves asymptotic or perturbation expansions and estimates. These are obviously his favorite mathematical topics and tools. The only reservation he has about mathematics, however, is that he said he would never read any math papers containing backward E's $(\exists)$ and upside down A's $(\forall)$. I retorted that those are merely the mathematician's way of simplifying repetitive wordings. If you insist on writing mathematics in a cumbersome way, I laughed, nobody can stop you.

Dr. Scully prefers the group mode of operation. When promising new topics emerge or when he or his collaborators encounter technical difficulties, he will call a group meeting of faculty, visitors, postdocs, and Ph.D. students. This sometimes numbers thirty people or more. At such group discussions you are witness to many anecdotes, hunches, critiques, pro and con arguments back and forth, much of which cannot be found anywhere in textbooks or the literature. It is very hard for one not to be stimulated. There is often pizza, sandwiches, or BBQ catering. Such meetings can last several hours.

One of the first research activities I participated in was a research project on quantum computing. Dr. Scully would ask people to give tutorials on this subject at a rather rudimentary level so that even "dummies" could understand. He then would hand out organized notes or relevant papers for every participant to read. Further, a set of new problems or assignments was distributed to the group, and the next meeting would be called the following day if he was not travelling.

This is a highly effective way of conducting physics research, where the timing and speed of research publication is everything. For physicists, there is really a sense of urgency permeating the atmosphere. Stress seems to be inevitable. Postdocs and Ph.D. students were chewed out if no good results were produced overnight. Conversely, anyone having made significant progress would be lavished with praise. He occasionally also called me at home late in the night to discuss problems or to check on progress.

A \$2M federal funding grant for five years to support quantum computing research for this group came through from DARPA, of which I was a member. Even though my summer salary in that grant was only budgeted for one month per year, Dr. Scully was very generous and actually provided me with three months of summer salary per year by supplementing from his other funding for two years in a row. Those were very successful years for securing funding in his career, and I benefitted from riding his coattails. Through group meetings, workshops, and semiannual reviews by the funding sponsors, and also through my interactions with him, his group, and his and my own Ph.D. students, I gained a substantial knowledge and understanding of quantum computing as well as of quantum mechanics in general. The cumulative outcome of this research support on quantum computing was that I managed to get about a dozen papers published, a U.S. patent approved, and a monograph on quantum computing devices 
(Chen, Church, Englert, Henkel, Rohwedder, Scully, and Zubairy [14]) published, which was the first monograph on this topic.

The domestic terrorism due to the mailing of white anthrax powder and the resulting fatalities generated considerable fear in homeland security. Dr. Scully, as a laser physicist, understood that an ultrafast laser application, called FAST CARS (femtosecond adaptive spectroscopic technique for coherent anti-Stokes Raman spectroscopy), could be useful. Nevertheless, in order to pursue this research, he needed to develop an even deeper understanding of chemical physics and physical chemistry (ChemPhysChem). So, during the summers of 2003 and 2004, he essentially stopped all of his summer travel and stayed home to work with his collaborators, Ph.D. students and postdocs, including me, on ChemPhysChem. We carefully went through the hydrogen atom and molecules, spins and symmetries, molecular bonds and orbitals, electronic structures, numerical modeling of simple bonds and calculations, etc. There was barely a summer day when I was at leisure for nonacademic recreation. At the end of summer 2004, I felt that I had learned a lot about ChemPhysChem (as a mathematician). A major outcome of the two summers of work was a long (145-page) article in [15], for which I was the lead author, although my role was somewhat like that of scribe and editor in putting that work together.

One of the easiest places to catch Dr. Scully is in the hallway of the physics building, where he can be seen discussing problems with his associates almost all the time. The stunning intensity and vigor with which he works are unrivaled among us. It is a joy to work with a genuine lover of physics and mathematics like him.

\section{Dr. Zhigang Zhang, Former Control Engineer}

I met Mr. Zhang for the first time in 2000 when I attended an engineering conference at the University of Science and Technology of China (USTC) in the city of Hefei, China. USTC is one of the leading technological universities in mainland China. Mr. Zhang served as my local host at the conference. He was a lecturer in the Department of Automatic Control Engineering at USTC, with a master's degree. He had been teaching at his alma mater for several years already.

In China the existence of automatic control engineering departments is still quite common even today, although in the U.S. automatic control engineering is just a part of the electrical engineering department. In control engineering papers (such as those published in IEEE Transactions on Automatic Control), the use of graduate-level operator theory, semigroups, and functional analysis is widespread, so that authors are usually quite well equipped with sound training in the core curriculum of graduate-level mathematics.

I propositioned Mr. Zhang that I would be happy to recruit him to study for his Ph.D. with me in the math department at Texas A\&M. He gladly agreed. Within a few months, a graduate assistantship from our Math Department was successfully arranged. So he came.

Mr. Zhang said he experienced "culture shock" while in graduate study at the math department of Texas A\&M University when he first came. But he studied well and, within two years, he passed the three qualifying exams-all in one try. (Our failure rate is actually quite high.) So he began to do research and wrote his dissertation.

During that period I was heavily involved in research on quantum computing and chemical physics. Mr. Zhang had solid training in atomic physics as well as in electronic and computer circuit design, so he readily provided help whenever I encountered difficulties in trying to understand physics, chemistry, and computing in my own work. To further prepare his interdisciplinary training, I advised him to take "quantum optics" graduate courses in the physics department and to take molecular computation training offered by the chemistry department. Mr. Zhang did marvelously well in those courses and training. He then tutored me whenever and wherever I needed help. He was one of the Ph.D. students who assisted me most during that period of my career. He was my tutor and study pal.

Upon graduation in 2006, Mr. Zhang became Dr. Zhang. He and I have collaborated on more than half a dozen papers, most of them related either to quantum computing or to atomic/molecular mathematical physics. Dr. Zhang subsequently did postdoctoral work for five years at the University of Houston. He is now working for a consulting company in Houston.

I have directed a total of four Ph.D. students whose undergraduate majors were not math. Doing a math Ph.D. may not have been their \#1 choice-as, for example, in Dr. Zhang's case-as it would have been quite difficult for him to secure a graduate assistantship from an electrical engineering department in the United States. But he excelled in studying math at Texas A\&M, and he, in turn, helped my own interdisciplinary research.

This is also a great opportunity for me to thank the Graduate Studies Committee of Texas A\&M University's math department for their financial support of several Ph.D. students that I have recruited. 


\section{Dr. Dudley Herschbach, Chemist}

Dr. Herschbach is a legend. He grew up in a bluecollar family near San Jose, California, and nobody else in his family had ever attended college. His father was a contractor who later turned to rabbit breeding. When Dr. Herschbach was young, he helped out the family by working after school. He recalled that the San Jose area used to have many orchards, and he spent summer months picking fruit in order to help with the family's income. But, since childhood, he had always loved science. Many nights he would climb trees to gaze at the stars. He was tall and athletic. He excelled in sports in high school. Upon graduation, he was offered two scholarships: one football and one academic at Stanford. He chose the latter, as the stipends were slightly more generous. (Nowadays, the opposite is mostly true: athletic scholarships are much more generous than academic scholarships.) He played the position of right end for the Stanford Indians (now called the Stanford Cardinal).

At Stanford, Dr. Herschbach studied earnestly in addition to playing football. He loved math and chemistry. He told me that he enjoyed the teaching of Pólya and Szegó in the math department so much that he loaded up his curriculum with the courses taught by these two math professors. After the end of his freshman year, Dr. Herschbach told his football coach that he would be quitting the team. His coach was quite shocked that he would give up the potentially lucrative career of a football player to do something else. Notwithstanding, Dr. Herschbach still received an invitation to try out for the Los Angeles Rams; he declined.

Dr. Herschbach's own higher-education training exemplified interdisciplinarity: he earned a B.S. in mathematics in 1954 and an M.S. in chemistry in 1955 , both from Stanford, and an M.A. in physics in 1956 and a Ph.D. in chemical physics in 1958 from Harvard. (Today, the divisions and specializations of various disciplines in science and mathematics are far deeper and wider than they were half a century ago, so that it would be virtually impossible to accomplish such a feat, even for a bright soul, without overtaxing him/herself. Dr. Herschbach is one of the very few I know of who hold such diverse advanced degrees.) Afterwards, he taught at Berkeley and then returned to Harvard. Still in his early thirties, he was elected to the National Academy of Sciences. He received a Nobel Prize in chemistry when he was in his mid-fifties. His nature is cheerful and unassuming. When one expresses admiration for his brilliance and Nobel stature, his "standard" response is always, "It was unintended." Dr. Herschbach has written over four hundred papers. His writings are characterized by the use of sophisticated mathematics, far exceeding the norm in chemistry. It is evident that mathematics has exerted a great influence on the thinking, reasoning, and style of his research. $\mathrm{He}$ is also a poet. He read a few of his poems to us, and they sounded quite fun. I once wrote an article and put his name down as a coauthor, hoping that he would consent. He offered many helpful and valuable ideas. He also helped to edit it. When I incorporated the changes he suggested in key words and sentences, the article's literary quality was dramatically improved. However, he adamantly refused to be listed as a coauthor, and, much to my dismay, I had to remove his name.

Dr. Herschbach was hired from Harvard by Texas A\&M in 2005 through the efforts of Dr. Scully (from above) in order to further strengthen the research in chemical physics at TAMU. His arrival on campus has spurred new and greater activity in this direction at the Institute for Quantum Science and Engineering. Dr. Herschbach has given us periodic lectures as well as small group tutorials on dimensional scaling (D-scaling) methods in chemical physics, for which he is a founder. This method was first suggested by G. 't Hooft (Nobel Prize in physics, 1999), motivated by quantum chromodynamics and discussed by E. Witten [17]. It embeds a quantum particle from space dimension 3 into space dimension $\mathrm{N}$ and lets $\mathrm{N}$ tend to infinity. It is rich in mathematical subtleties related to the multiparticle Schrödinger equation and is powerful and challenging. He pointed out to me that the singular perturbation procedures therein require rigorous mathematical justification. Under his tutelage, my collaborators and I have succeeded in justifying some of the D-scaling procedures for special cases of the hydrogen atom and the power-law potentials [5], [6]. The general cases are definitely far more challenging and will likely take a long time to resolve.

So far, I have coauthored two papers with Dr. Herschbach [5], [18]. I cannot equate the coauthorship with being an intellectual equal of his on the topic of chemical physics. I think of it as doing an apprenticeship with him, because he has taught me so many things that I cannot learn anywhere else, just like the apprenticeship that I did under Dr. Scully.

Dr. Herschbach has just celebrated his eightieth birthday (2012). He continues to do research. He is also active in science education, arms control and nonproliferation, peaceful negotiations between the Israelis and Palestinians, and other areas. For me, I hope that there will continue to be many opportunities to study with him and to write more joint papers. 


\section{Concluding Remarks}

It is the author's great fortune to have met so many wonderful collaborators, mathematicians, and interdisciplinarians alike in his career so far. It is fun to collaborate, learn, and get help from your partners and expedite research work. Indeed, in a collaboration of any kind, whether inter- or intradisciplinary, we benefit from our partners. Nevertheless, I am inclined to feel that such benefits appear greater in interdisciplinary research, as we need more help and guidance when we enter large, uncharted territories that are outside our traditional disciplinary zone of comfort, given the condition that our interdisciplinary research collaborators can always be standing by, just an email or a phone call away, to offer assistance.

Interdisciplinary research is a two-way street: we take and we give. Again, from the stories I have told above, I have been blessed by the generosity of my interdisciplinary research mentors, colleagues, and students. Even though I always try to reciprocate in kind, I am not sure if I have indeed paid back enough.

I also have had a few interdisciplinary research endeavors that went nowhere. There were several reasons, I believe, why they did not succeed:

(a) The problem selections and objectives were not sharply delineated at the outset. Oftentimes, envisioned approaches did not pan out. Directions of work were constantly shifting, causing confusion and discontinuities. Initial excitement dwindled with time, while no new enthusiasm emerged.

(b) The problem scope was large and the target ambitious. Much manpower was needed, yet there was no funding to get things off the ground or no way to find partners with the desired specialties or strong commitment.

(c) For new potential partners, sometimes close rapport and confidence could not be built or made to last. Personality mismatch can be a big turnoff. Fighting for/over individual credits and authorship rankings should be taboo. I tend to go straight to those who are my long-time friends for help.

(d) I cannot commit enough time and energy to satisfy the needs of many new projects due to other pursuits and daily pressing duties.

Despite certain failures, I rate my own past interdisciplinary research as happy and successful. Through collaborations with my interdisciplinary research partners, I have been able to achieve many successes, far outnumbering the failures. Their contributions have helped to steer the directions of my research and also shape what I am today. It has been, and continues to be, a unique, life-enriching experience.

\section{Acknowledgments}

The author wishes to thank two anonymous reviewers for constructive criticisms and Professors Matthew P. Coleman and David L. Russell for helpful editorial comments.

\section{References}

[1] Why Interdisciplinary Research? http://www. beckmanmacular.org/site/DocServer/ Info_on_IDR.pdf?docID=121

[2] Committee on Facilitating Interdisciplinary Research, National Academy of Sciences, National Academy of Engineering, Institute of Medicine, Facilitating Interdisciplinary Research, The National Academy Press, Washington, DC, 2004.

[3] T. A. HEBERLEIN, Improving interdisciplinary research: Integrating the social and natural sciences, Society and Natural Resources 1 (1988), 5-16.

[4] C. M. GoldE and H. Alix GallagheR, The challenges of conducting interdisciplinary research in traditional doctoral programs, Ecosystems 2 (1999), 281-285.

[5] G. Chen, Z. Ding, C.-S. Lin, D. Herschbach, and M. O. SCUlly, Variational justification of the dimensional scaling method in chemical physics: The H-atom, J. Math. Chem. 48 (2010), 791-811.

[6] Z. DING, G. CHEN, and C.-S. LIN, Mathematical analysis of the dimensional scaling technique for the Schrödinger equation with power-law potentials, J. Math. Phys. 51 (2010), 123508.

[7] LISA M. CAMPBELL, Overcoming obstacles to interdisciplinary research, Conservation Biology 19 (2005), 574-577.

[8] D. RHOTEN and A. PARKeR, Education: Risks and rewards of an interdisciplinary research path, Science 306 (2004), 2046.

[9] L. R. LATTUCA, Creating Interdisciplinarity: Interdisciplinary Research and Teaching among College and University Faculty, Vanderbilt University Press, 2001.

[10] N. METZGER and R. N. ZANE, Interdisciplinary research: From belief to reality, Science 283 (1999), 642-643.

[11] L. H. BEARINGER, Interdisciplinary Research Articles (compiled by L. H. Bearinger), http://www. grad.umn.edu/oii/workshops/documents/ Interdisciplinaryreferencelist.doc.

[12] G. CHEN and J. ZHOU, Boundary Element Methods, Academic Press, London-San Diego, 1991.

[13] _ Boundary Element Methods with Applications to Nonlinear Problems, Atlantis Press, Paris, 2011.

[14] G. Chen, D. A. Church, B.-G. Englert, C. Henkel, B. ROWEDDER, M. O. SCUlly, and M. S. Zubairy, Quantum Computing Devices: Principles, Designs and Analysis, Chapman \& Hall/CRC Press, Boca Raton, FL, 2006.

[15] G. Chen, S. A. Chin, Y. Dou, K. T. Kapale, M. Kim, A. A. Svidzinsky, K. URTEKIN, H. XiOnG, and M. O. SCULLY, The two electron molecular bond revisited: From Bohr orbits to two-center orbitals, in Advances in Atomic, Molecular, and Optical Physics, 51, Elsevier, New York, 2005, pp. 93-238.

[16] C. ReID, Hilbert, Springer, New York, 1996.

[17] E. WitTEN, Quarks, atoms, and the $1 / \mathrm{N}$ expansion, Phys. Today 33 (1980), 38.

[18] A. Svidzinsky, G. Chen, S. Chin, M. Kim, D. Ma, R. Murawski, A. Sergeev, M. O. Scully, and D. HERSCHBACH, Bohr model and dimensional scaling analysis of atoms and molecules, Int. Rev. Phys. Chem. 27 (2008), 665-723. 